\title{
TENSION COMPONENTS AND TENSION FALL OF THE BULLFROG ATRIAL MUSCLE DURING DEPOLARIZATION
}

\author{
Masayosi Goto, Yasuo WAdA, and Masahiko SAIto \\ Department of Physiology, School of Medicine, \\ Kyushu University, Fukuoka, Japan
}

\begin{abstract}
Summary 1) Development and fall of tension during depolarization in the bullfrog atrial muscle were studied using a double gap voltage clamp arrangement.
\end{abstract}

2) Phasic and tonic tension developments and the following decay were noticed in the tension produced by depolarizing pulse of different durations and amplitudes. The phasic component appeared in response to a short-lasting pulse $(0.1-0.2 \mathrm{sec})$, and reached a peak tension at around $73 \mathrm{mV}$ depolarization, being depressed for stronger pulses. La (1 mM) and $\mathrm{Mn}$ ions (5 mM) eliminated the component.

3) Tonic contraction was generated by long-lasting depolarization. The development of tension was not affected by these ions, but increased in strength and duration of depolarizing pulse up to $170 \mathrm{mV}$ and $1.0 \mathrm{sec}$. 4) When a depolarizing pulse was sustained, the tonic tension decayed gradually after the peak. The tension decay was composed of three different phases, initial retardation, relatively rapid relaxation and extremely slow final relaxation.

5) The rapid relaxation phase appeared exponential with time when an excess tension above provisional final tension (sustained tension) was plotted, but the time constant increased with strength of depolarization.

6) Logarithm of the final tension appeared proportional to the membrane depolarization in between 20 to $100 \mathrm{mV}$. Under the simultaneous presence of $\mathrm{La}(1 \mathrm{mM})$ and caffeine $(10 \mathrm{~mm})$ the tension decay during depolarization was abolished resulting in a marked elevation of the final tension.

7) The final tension under normal conditions was considered to be equilibrium tension between the tonic tension and relaxing components, and thus, at least three components, the phasic and tonic tensions and a relaxing factor, appeared to control muscle contraction during depola-

Received for publication February 12, 1974

後藤昌義, 和田泰男, 斎藤雅彦 
rization.

In various mammalian heart muscle a biphasic contraction, an initial twitch followed by a tonic tension development in response to long-lasting depolarization, has been elucidated with voltage clamp studies (McGuIGAN, 1968; Fozzard and Hellam, 1968; Beeler and Reuter, 1970; Gibbons and Fozzard, 1971; OChi and Trautwein, 1971; OHBA, 1973). The contractile response to long depolarization of moderate intensity is a twitch with full relaxation, while strong depolarization induces a second tonic contraction which is sustained for the whole duration of depolarization. OCHI and TRAUTWEIN (1971) and recently TritTHART et al. (1973) noticed that the initial twitch tension is composed of two elements, one related to a Ca inward current, as first elucidated by REUTER and BEELER (1969), and the other, to membrane depolarization or active $\mathrm{Na}$ inward current.

In amphibian myocardium, in which distinct ultrastructures, different from those in mammalia were shown (STALEY and BENSON, 1968; SOMMER and JoHNSON, 1969), MORAD and ORKAND (1971) observed that contraction of frog ventricular muscle in response to depolarization is solely due to a tonic mechanism which is controlled by the membrane potential. In the atrial muscle, however, tension elicited by depolarizing pulse has been found to be composed of two elements (VASSORT and ROUGIER, 1972; LÉOTY and REYMOND, 1972; EINWÄCHTER et al., 1972), one phasic component depending on the $\mathrm{Ca}$ inward current and the other tonic one unclarified in nature.

The present experiment aims at a further clarification of the nature of these tension components in bullfrog atrial muscle, and a more detailed analysis of the time-course of tension development and fall during depolarization. The results obtained indicate a presence of phasic, tonic and final tension components, suggesting the operation of three mechanisms which control muscle tension.

\section{METHODS}

Muscle bundles, $4-5 \mathrm{~mm}$ long, $0.3 \mathrm{~mm}$ thick and $1.5 \mathrm{~mm}$ wide were isolated from the bullfrog atrium, and the epicardium as well as connective and fat tissues were eliminated. The chamber in which the preparation was mounted (Fig. 1) was a modification of that used originally by RoUGIER et al. (1969), and consisted of five Lucite compartments $(1,2,3,4,5)$ separated by four diaphragms with holes in the center. Two of the diaphragms between the central (3) and terminal compartments (1) were composed of each three close fitting, slotted plates and utilized for the fixation of the preparation. The other two were rubber membranes and the rest of muscle bundle was pulled through the tightly closed holes and connected to the sensitive arm of a strain gauge (Nihon Kohden SB-1T) for tension measurement in the other terminal compartment (5). Compartments 


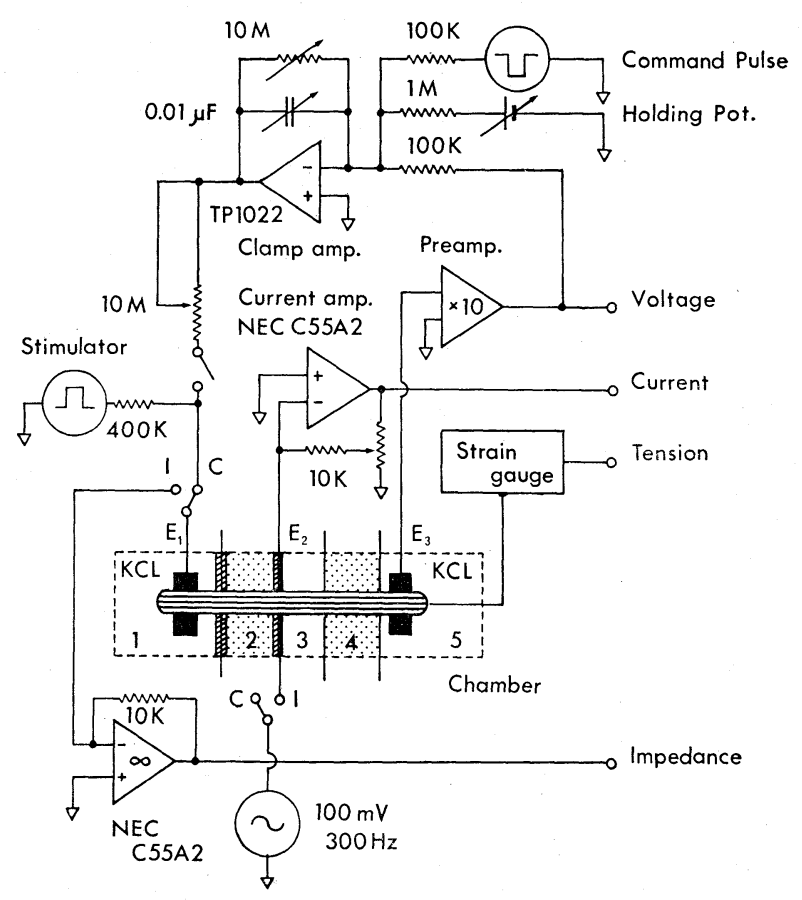

Fig. 1. Schematicillustration of the experimental circuit and chamber. The chamber consists of five compartments $(1,2,3,4$, and 5$)$ with four diaphragms, two of which are rubber membranes (vertical lines) and the other two slotted thin celluloid plates (hatched parts). Black rectangles show $\mathrm{Ag}-\mathrm{AgCl}$ plate electrodes $\left(\mathrm{E}_{1}, \mathrm{E}_{2}\right.$, and $\left.\mathrm{E}_{3}\right)$. The experimental circuit consists of five sections, voltage, current, tension and impedance (I) measurements and voltage clamp system (C). Further explanations are in text.

1, 3, and 5 had $\mathrm{Ag}-\mathrm{AgCl}$ plate electrodes $\mathrm{E}_{1}, \mathrm{E}_{2}$, and $\mathrm{E}_{3}$, respectively.

The terminal compartments $(1,5)$ were large pools $\left(10 \times 5 \times 5 \mathrm{~mm}^{3}\right)$, filled with $190 \mathrm{~mm} \mathrm{KCl}$ solution, instead of an isotonic one, to render those parts of preparation completely depolarized and inexcitable. Intermediate compartments $(2,4)$, each $1 \mathrm{~mm}$ in width, were perfused with isotonic glycerol solution $(246.5 \mathrm{~mm})$ instead of sucrose solution. The central compartment (3) $0.3-0.6 \mathrm{~mm}$ in width was perfused with normal Ringer's solution or test solution. Composition of the normal Ringer's solution was as follows (mM/liter): $\mathrm{NaCl}, 109.84 ; \mathrm{KCl}, 2.56$; $\mathrm{NaHCO}_{3}, 2.38 ; \mathrm{CaCl}_{2}, 2.18 ; \mathrm{KH}_{2} \mathrm{PO}_{4}, 0.34$; glucose, 5.80 and $\mathrm{pH}$ was 7.3. Test solutions containing $\mathrm{MnCl}_{2}(5 \mathrm{~mm}), \mathrm{LaCl}_{3}(1 \mathrm{~mm})$ and/or caffeine (10 mM) were made simply by adding the drugs to the Ringer's solution. In such cases, however, Tris-buffered Ringer's solution with its $\mathrm{pH}$ adjusted was used as control as well as the base of test solutions.

A gap potential difference was obtained between compartments 3 and $5\left(E_{2}\right.$ and $\left.E_{3}\right)$, while feedback current was applied between compartments 1 and $3\left(E_{1}\right.$ 
and $\mathrm{E}_{2}$ ). The electrical circuits for measurement of the voltage and current and for clamping the membrane potential (Fig. 1) were fundamentally the same to those used by New and Trautwern (1972a) on the cat ventricle. A high-voltage operational amplifier, Teledyne-Philbrick 1022, enabled the supplying of enough feedback current in the input voltage range of $\pm 200 \mathrm{mV}$. In our experiments on the bullfrog atrium, however, an overvoltage detector was not used because of the better stability of the double gap method and the slower rate of the rise of action potential than those obtainable with a microelectrode in the mammalian myocardium.

Basal driving frequency with a stimulator was 0.1 cycle per sec. When the membrane potential was clamped (C), the potential was usually held at the resting gap potential, and a depolarizing pulse of different intensity and duration, with or without combination of second clamp step, was given regularly at the basal frequency except the cases otherwise noted. Impedance measurement (I) was occasionally done when a check of the state of the preparation was desired (New and Trautwein, 1972a).

Experiments were started about $30 \mathrm{~min}$ after the initiation of perfusion. At this time most of preparations exhibited monophasic action potentials even if the terminal compartments (5) was perfused with normal Ringer's solution. Action potentials of more than $100 \mathrm{mV}$ were common with this method, and preparations which showed either a gap potential less than $65 \mathrm{mV}$ or an action potential less than $80 \mathrm{mV}$ were discarded. The steady tension was adjusted to be $0.1-0.2 \mathrm{~g}$ at which twitch tension became nearly maximum. Further notes and possible experimental errors with our double gap method were discussed in preceding reports (Gото et al., 1971; 1972). All experiments were done at temperatures $20 \pm 2{ }^{\circ} \mathrm{C}$ which were adjusted with a thermoregulator.

\section{RESULTS}

1. Two components of tension development of the bullfrog atrial muscle in response to depolarization

Voltage-tension relationships in the atrial muscle were studied with rectangular depolarizing pulses of differing intensity and duration. More than 20 series out of 32 experiments were successful. Figure 2 shows an example of typical records in which the holding potential (original gap potential) was $-75 \mathrm{mV}$. When a short pulse duration of $0.15 \mathrm{sec}$ was used (Fig. 2A), most of tension developed after the pulse, accompanying a tail of active inward current. The maximum rate of rise of tension increased and the time to peak tension from the onset of pulse decreased with amplitude of depolarization. The decrease in the time to peak was partly due to a shortening of latency of the active current. When the pulse duration was increased to $0.5 \mathrm{sec}$ (Fig. 2B) the tail of active inward current diminished, but the peak tension appeared still delayed after the pulse. 
The rate of rise of tension increased with depolarization. The time to peak tension, however, was markedly prolonged for stronger depolarizations, suggesting an addition of new tension component. The peak tension elicited by the same grade of depolarization was larger than that for $0.15 \mathrm{sec}$ pulse.
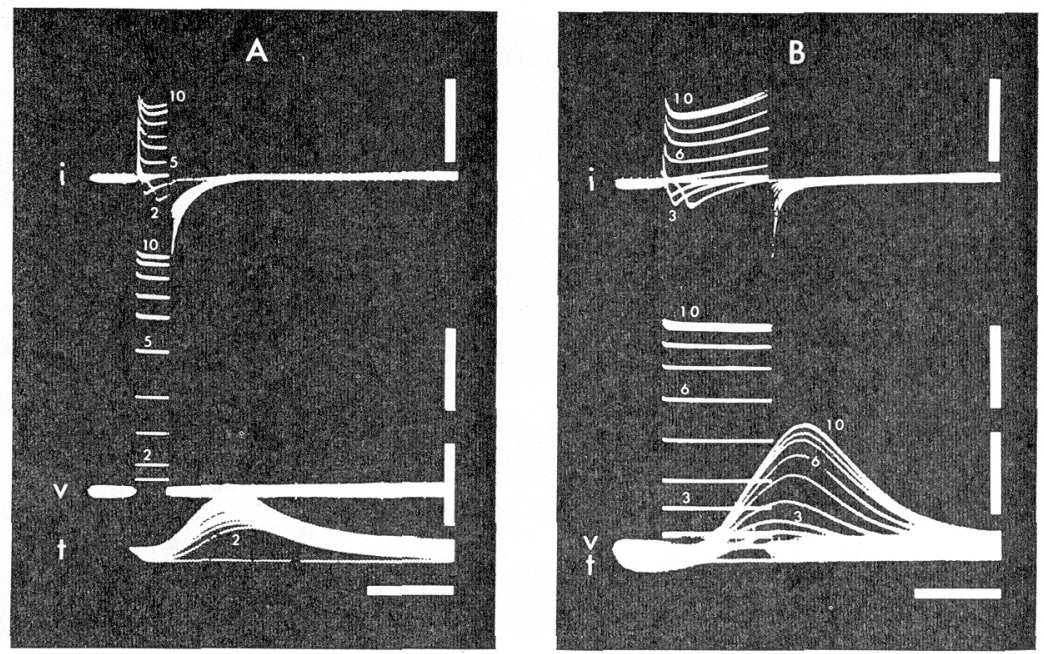

Fig. 2. Configuration of contraction in response to depolarization of increasing intensity and duration. A) Responses to $0.15 \mathrm{sec}$; B) $0.5 \mathrm{sec}$ depolarizing pulses. Top, middle and bottom tracings show membrane currents (i), voltages (v) and tensions ( $\mathrm{t}$ ), respectively. In each series, as shown labeled with mumber, the depolarizing pulse was gradually strengthened. Holding potential was $-75 \mathrm{mV}$. Horizontal bar is calibration of $0.4 \mathrm{sec}$. Vertical bars are those of $50 \mu \mathrm{A}, 50 \mathrm{mV}$ and $0.1 \mathrm{~g}$ for the current, voltage and tension records, respectively. Note a shift of peak tension depending on the strength and duration of depolarizing pulse.

When longer pulses of $1.0 \mathrm{sec}$ were used, the peak tensions were augmented further and often appeared with a step in the rising phase. The time to peak tension of about $0.6 \mathrm{sec}$ for weak depolarizations below $70 \mathrm{mV}$ suddenly shifted to a markedly larger value of about $1.1 \mathrm{sec}$ for stronger depolarizations (Fig. 4A). In these cases, the augmentation of tension was produced generally with a constant initial rate of rise but with an inhibition in the rate of fall from the first peak or further with an addition of increasing tension toward the end of depolarization. These observations, especially a sudden shift of the peak from the first to the second, strongly suggest that two components exist in the tension development for long and strong depolarization.

The evidences of two tension components were also obtained by examining the voltage-peak tension relationship. Figure $3 \mathrm{~A}$ shows the data in which step pulses up to $170 \mathrm{mV}$ depolarization of three different durations, $0.2,0.4$, and $1.0 \mathrm{sec}$ were applied. The holding potential was $-70 \mathrm{mV}$ throughout. In each series, 
the pulse voltages were gradually increased and then decreased in a similar fashion. The peak tension responses for different pulse durations, however, appeared quite differently. The pulses of $0.2 \mathrm{sec}$ produced a series of tension responses with a central dip indicating a decrease in peak tension for stronger voltages, while $1.0 \mathrm{sec}$ pulses elicited dome-type responses showing an increase in the tension with increasing voltages. The responses to $0.4 \mathrm{sec}$ pulses appeared rather flat and intermediate in the pattern.

A

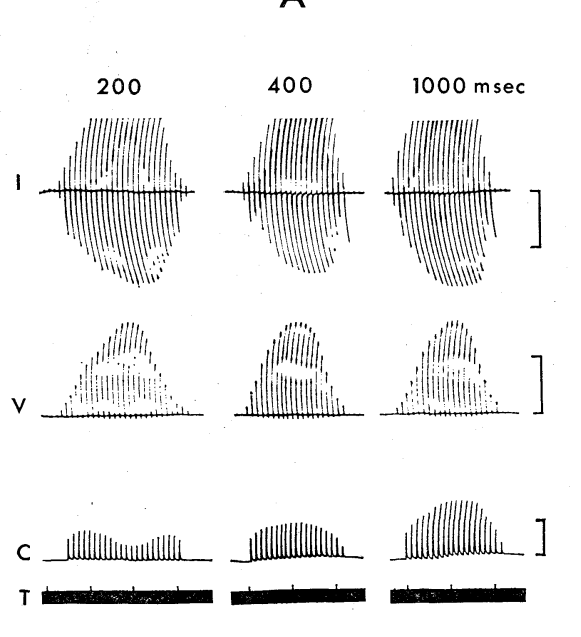

B

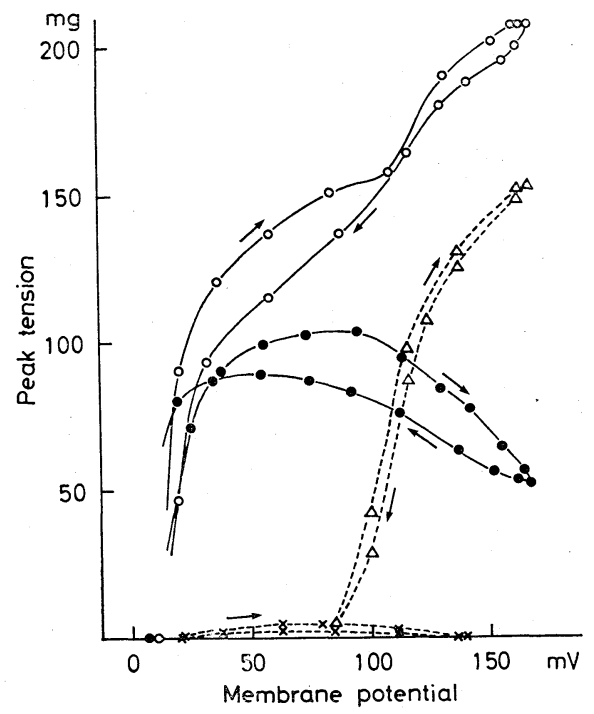

Fig. 3. Voltage-peak tension relationship of the bullfrog atrial muscle. A) Simultaneous slow recordings of the current (I), voltage $(\mathrm{V})$ and tension (C) on the inkwriting oscillograph. Responses to a series of increasing and decreasing depolarizing pulses with three different durations, $0.2,0.4$, and $1.0 \mathrm{sec}$, are shown. Holding potential was $-70 \mathrm{mV}$ throughout. Time calibration (T) is $1.0 \mathrm{~min}$. Vertical bars are calibrations of $20 \mu \mathrm{A}$, $100 \mathrm{mV}$ and $0.1 \mathrm{~g}$ for the current, voltage and tension records, respectively. B) Relation between the peak tension and membrane depolarization. Abscissa shows the amplitude of depolarizing pulse taking the holding potential level as zero. Filled circles denote peak tensions in response to $0.2 \mathrm{sec}$ depolarizing pulses, and open circles, those to $1.0 \mathrm{sec}$ pulses. Arrows show experimental orders. Crosses and triangles with broken lines show corresponding data under action of $\mathrm{La}(1 \mathrm{mM})$ obtained with 0.2 and $1.0 \mathrm{sec}$ pulses, respectively. Explanations are in text.

The voltage-peak tension relationships for 0.2 and $1.0 \mathrm{sec}$ pulses were plotted in Fig. 3B. Despite the appearance of considerable hysteresis due to successive application of depolarizations, a maximal tension for $0.2 \mathrm{sec}$ pulses was attained at around $60-90 \mathrm{mV}(73 \pm 11 \mathrm{mV}$ as a mean with $\mathrm{SD}$ of 5 experiments), and above these voltages the tension decreased gradually with increasing depolarization. While, for $1.0 \mathrm{sec}$ pulses, the peak tension continued to increase with 
amplitude of depolarization up to $170 \mathrm{mV}$ but with a step at around $110 \mathrm{mV}$ in the relationship. The tension, however, gradually saturated or rather decreased toward the $210 \mathrm{mV}$ depolarization examined in other preparations.

These voltage-tension relationships were simplified by an application of La (1 mM) which blocked the fast as well as slow active inward currents in this excess concentration. The effects in details will be reported in another paper (in preparation), but the voltage dependency of tension under the action of $\mathrm{La}$ is illustrated in Fig. 3 for comparison. As shown by the broken line, La abolished the contractile responses for shorter pulses, but generally did not affect the responses for longer ones. The contractile tension under the action of $\mathrm{La}$ increased with depolarization and when plotted against the voltage, produced an upperward convex curve without inducing the step mentioned. Similar data were also obtained with Mn (5 mm) as observed by VASSORT and Rougier (1972) and LÉOTY and REYMOND (1972) on the frog myocardium.

\section{Tension fall during long-lasting depolarization}

Figure 4B shows time-courses of contraction of the atrial muscle during longlasting depolarization of different intensity. The holding potential was $-68 \mathrm{mV}$ and step depolarizations of $15-110 \mathrm{mV}$ and $3.2 \mathrm{sec}$ duration were applied. The rate of rise of tension and the peak tension increased with strength of depolarization, and the first and the second peaks of tension were again visible. The developed tension, however, decayed slowly after the peaks despite the continuance of depolarization. Similar decays in tension have also been observed
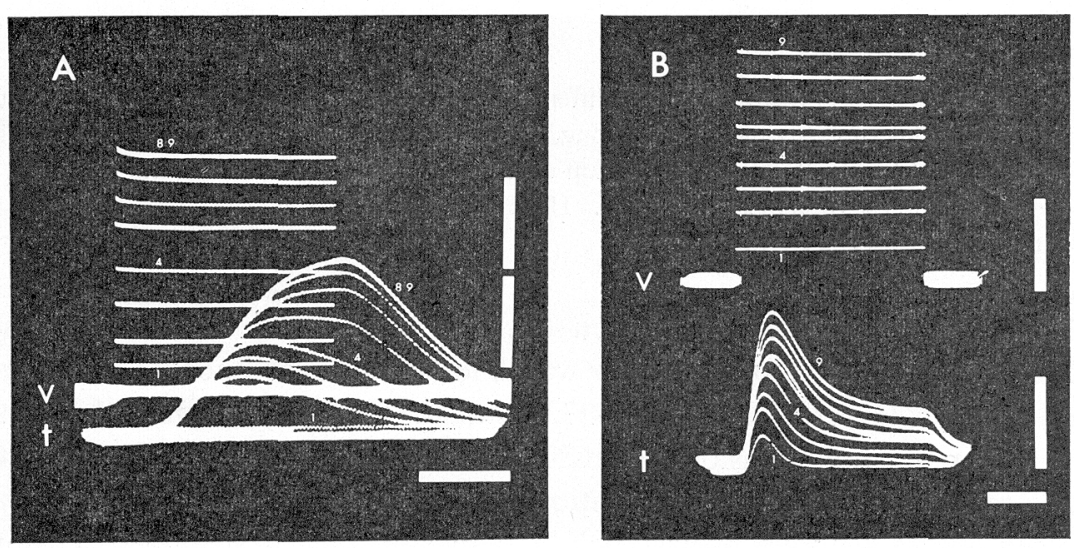

Fig. 4. Tension development and decay during long-lasting depolarization. A) Superimposed recordings of the responses to $1.0 \mathrm{sec}$; B) $3.2 \mathrm{sec}$ depolarizing pulses. Holding potential was $-68 \mathrm{mV}$, and depolarizing pulse of $15-110 \mathrm{mV}$ was given with a interval of $20 \mathrm{sec}$. The pulse was gradually strengthened as partly labeled. Horizonal bar is calibration of $0.4 \mathrm{sec}$ for $\mathrm{A}$ and $1.0 \mathrm{sec}$ for $\mathrm{B}$. Vertical bars, calibrations of $50 \mathrm{mV}$ and $0.1 \mathrm{~g}$ for the voltage $(v)$ and tension records $(t)$, respectively. 
in the bullfrog ventricle (Gото et al., 1971, Fig. 7) and in the atrium during depolarization with the voltage clamp (EINWÄCHTER et al., 1972), though the decays are small in grade.

In order to examine the time-course of tension development and decay in more detail, first the voltage-tension relationships at different time points after step depolarizations of different intensity were plotted as shown in Fig. 5. Up to $0.50 \mathrm{sec}$ after depolarization, when the first phasic tension component was dominant, upperward convex curves were obtained (Fig. 5A), while a short time later a gradual shift from the convex to concave curves occurred mainly due to the appearance of the second tonic tension which added more tension for stronger depolarization. In the following periods, the first phasic and then the second tonic tension components decayed gradually with time (Fig. 5B).

A

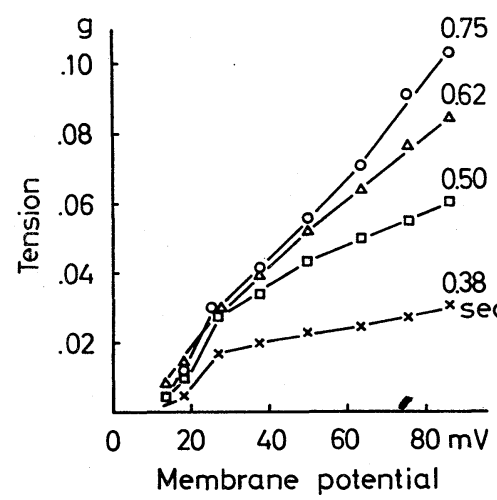

B

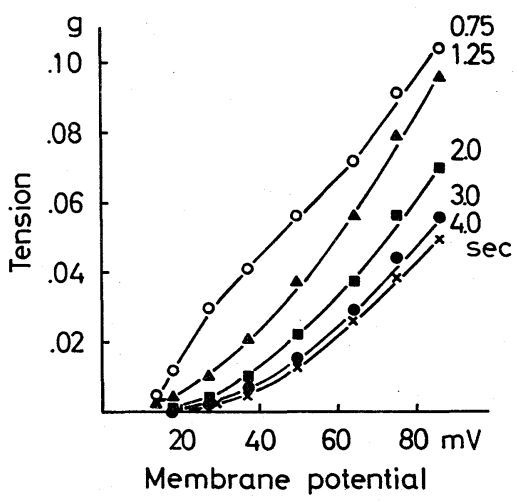

Fig. 5. Voltage-tension relationships at different times after depolarization. A mean values of three series of experiments with long depolarizing pulses were plotted. A) Tension development before $0.75 \mathrm{sec}$; B) tension decay thereafter. Numbers in the right side of curves denote the time in sec analysed. Holding potentials were $-67,-68$, and $-72 \mathrm{mV}$ but their differences were neglected.

Next, the time-course of tension decay was analysed. Since the tension fall after cessation of depolarization was known to be composed of a few exponential curves (Gото et al., 1971, 1972), similar analysis was made by plotting the logarithm of total tension against time after the onset of depolarization, but this resulted in complicated relationships. However, when a logarithm of excess tension $\left(T_{e}\right)$ above provisional final tension $\left(T_{f}\right.$, a sustained tension at the end of $4.0 \mathrm{sec}$ depolarization. See the next section) was plotted against time, the relationships became simpler and comparable to those of tension fall after repolarization.

Figure 6A shows one of the relationships obtained from a typical experiment in which the holding potential was $-73 \mathrm{mV}$ and step pulses of $8-77 \mathrm{mV}$ depolari- 
A

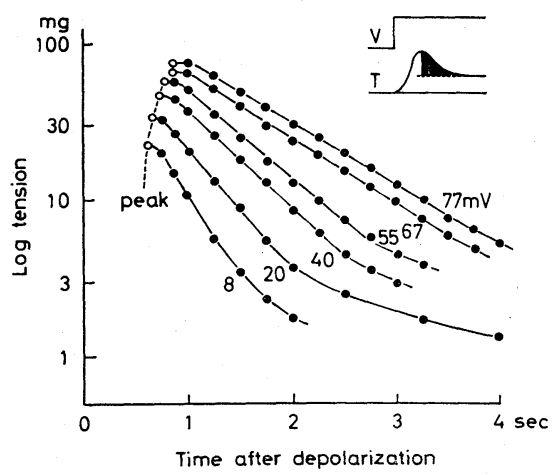

B

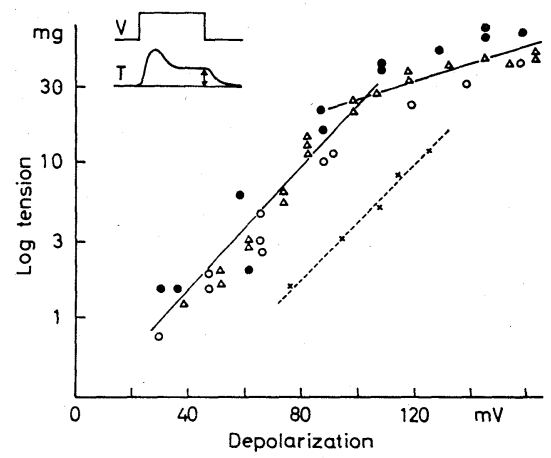

Fig. 6. A) Time-course of tension fall during depolarization. Logarithm of excess tension above provisional final tension (see the inset and text) was plotted against time after the onset of depolarization. The curve obtained follows an exponential relationship, increasing the time constant with strength of depolarization. B) Dependency of the logarithm of provisional final tension on the membrane potential. Data from three different preparations were plotted. Broken line with crosses shows the relationship in Calack $(0.22 \mathrm{~mm})$ Ringer's solution on the same preparation plotted with open circles. Holding potential was $-70 \mathrm{mV}$ in $\mathrm{A}$ and $-68(\bullet),-70(\mathrm{O})$ and $-74 \mathrm{mV}(\triangle)$ in B. Continuous and dotted lines were drawn with eye.

zation and $4.0 \mathrm{sec}$ duration were applied. The time to peak tension from the onset of pulse was prolonged with strengthening of the depolarization, though separation of the first and second peaks was not clear in these plots. The tension fall, however, appeared roughly exponential with time, except for a delay at initial period of $0.2 \mathrm{sec}$ after the peak and a slow decay at terminal phase. Similar relationships were obtained in two other series of experiments analysed, and the exponential relationship was found to be kept longer when the depolarization was stronger, and generally continued up to the end of $4.0 \mathrm{sec}$ pulse in cases of depolarization of more than $60 \mathrm{mV}$. Thus, during the exponential decay, the excess tension could be expressed as follows,

$$
T_{e}=\left(T_{m}-T_{f}\right) e^{-t / \tau_{1}}
$$

and hence,

$$
d T_{e} / d t=-1 / \tau_{1} \cdot\left(T_{m}-T_{f}\right) e^{-t / \tau_{1}}
$$

in which $t$ denotes the time after the peak, $\tau_{1}$, the time constant of tension decay, and $T_{m}$, the maximal tension obtained by extrapolation of the linear relationship to zero time of peak tension. These equations mean that not only the excess tension $\left(T_{e}\right)$ but also the rate of decay of the excess tension $\left(d T_{e} / d t\right)$ are exponential with time and proportional to the difference between the maximal tension and the provisional final tension $\left(T_{m}-T_{f}\right)$. In this special case, the time constants of exponential decay were $0.40,0.52,0.64,0.79,1.02$, and $1.25 \mathrm{sec}$ for 
$8,20,40,55,67$, and $77 \mathrm{mV}$ depolarizations, respectively. The increase in time constant with depolarization coinsided well with those in tension decay observed at differing potential levels after termination of depolarization (Goто et al., 1972, Fig. 6A). However, no abrupt change in the time constant between the tension falls from the fast and slow peaks was noticed as far as the rapid relaxation phase was concerned.

\section{Provisional final tension and the dependency on the membrane potential}

Final tensions at different membrane potential levels were difficult to determine, since the tension of normal atrial muscle, after showing a peak, continued to decay extremely slowly during sustained depolarization up to 70 seconds observed. Principal tension decay during sustained depolarization, however, occurred in a few seconds, and the rate of excess tension decay decreased exponentially with time as noted (Eq. 2). Thus, even in case of $70 \mathrm{mV}$ depolarization, the excess tension $\left(T_{\theta}\right)$ became less than 2 percent of the maximal tension $\left(T_{m}\right)$ at the end of $4.0 \mathrm{sec}$ depolarization. Therefore, taking the tonic tension at the end of pulse (see Fig. 9) as a provisional final tension $\left(T_{f}\right)$, relationship between $T_{f}$ and the membrane potential was studied.

In the lowest curve of Fig. 5B, the tension $4.0 \mathrm{sec}$ after depolarization increased gradually with increasing strength of depolarization. However, when the logarithm of tension was plotted against membrane potential, the relationship became more linear. Figure 6B shows the plots of data from three different preparations. A linear relationship was observable for voltages lower than $90 \mathrm{mV}$ depolarization (almost plateau potential level), but a considerable downward deviation occurred for stronger voltages. The deviation is not due to an increasing differences between the provisional and true final tensions in this potential range, since the difference would produce an upperward deviation. The cause of deviation is unknown at present, however, the relationship exactly corresponds to the data in our former report concerning the dependency of the final tension after repolarization on the membrane potential level (Gото et al., 1972).

\section{Tonic tension component during depolarization}

Time-course of the tonic tension development was analysed under simultaneous presence of tetrodotoxin $\left(10^{-8} \mathrm{mg} / \mathrm{ml}\right)$ and $\mathrm{Mn}(5 \mathrm{mM})$ or caffeine $(10 \mathrm{~mm})$ and $\mathrm{La}(1 \mathrm{mM})$. Figure $7 \mathrm{~A}$ shows the typical records obtained $15 \mathrm{~min}$ after application of the former drugs, in which the holding potential was $-65 \mathrm{mV}$ and step pulses of $1.0 \mathrm{sec}$ duration and differing intensity were given. For depolarizations above mechanical threshold, which was markedly elevated, developing tension rose gradually to reach a final value without accompanying active inward currents. The tonic tension, however, appeared closely related to an initiation of delayed outward current, as first denoted by LÉOTY and REYMOND (1972), but the details are not analysed in this paper. 
A

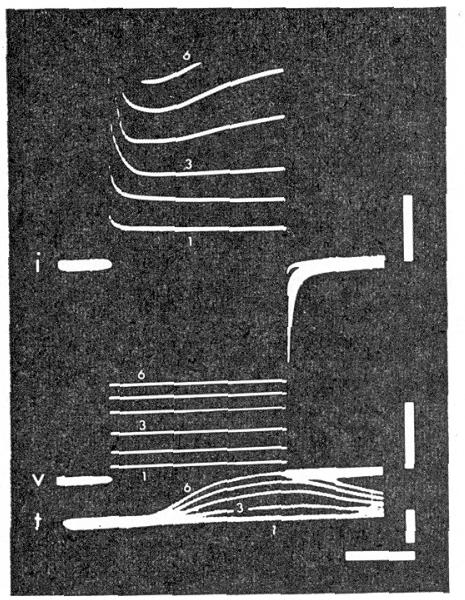

B

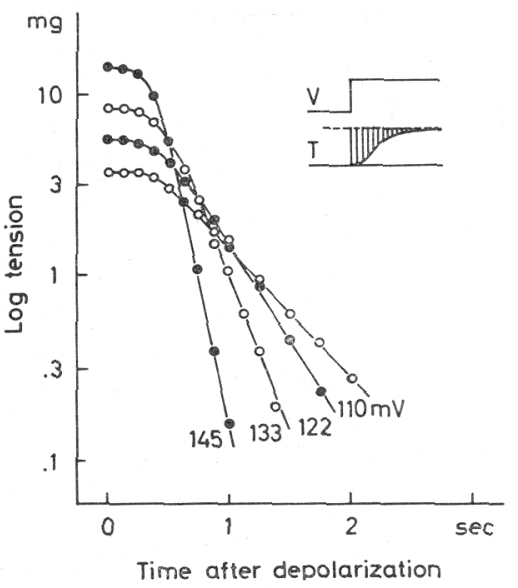

Fig. 7. A) Tonic tension development during long-lasting depolarization under simultaneous action of $\mathrm{Mn}(5 \mathrm{~mm})$ and tetrodotoxin $\left(10^{-7} \mathrm{~g} / \mathrm{ml}\right)$. The depolarizing pulse was gradually strengthened as partly labeled with number. Horizontal bar is a calibration of $0.4 \mathrm{sec}$, and vertical bars are calibrations of $20 \mu \mathrm{A}, 50 \mathrm{mV}$ and $0.01 \mathrm{~g}$ for current (i), voltage (v) and tension records ( $t$ ), respectively. Note an absence of inward currents and a parallel appearance of delayed outward current and tonic tension. B) An analysis of the time course of tension development under the same condition but on the other preparation. Logarithm of the difference between actual tension and provisional final tension was plotted against time after the onset of depolarization. Number aside the curve denotes the amplitude of depolarizing pulse.

The effects of caffeine and La on tension development are shown in Fig. 8, in which depolarization of $3.5-4.0 \mathrm{sec}$ are applied. The holding potential was $-68 \mathrm{mV}$. As can be seen, caffeine markedly increased the phasic and sustained tension components. A relaxation of tension during the long-lasting depolarization, however, occurred with increased time constants. $\mathrm{La}(1 \mathrm{mM})$, which is high enough in concentration to block the active sodium and calcium inward currents (Goto et al., unpublished observation), on the other hand, depressed the phasic tension almost completely while the sustained tension was unaffected. Under the simultaneous action of $\mathrm{La}$ and caffeine, the sustained tension rose markedly and no sign of relaxation occurred during the depolarization. The situation was the same even when the duration of pulse increased up to $30 \mathrm{sec}$ (the figure is not shown). These data again suggest that the tonic tension component is independent and different from the phasic component, and further that the sustained final tension level is determined by at least two factors, voltage dependence and the other independent but caffeine sensitive.

According to HAGIWARA et al. (1968) the time course of tension rise in the barnacle muscle can be described as two exponential components. Similar analysis was made on the tonic tension development. Figure 7B shows the data 
A

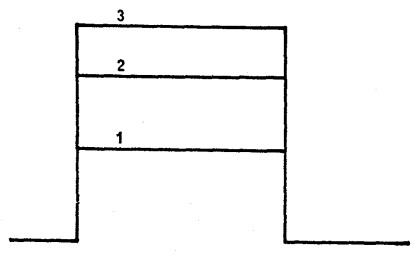

Normal

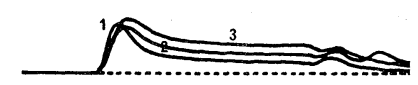

Caffeine $10 \mathrm{mM}$

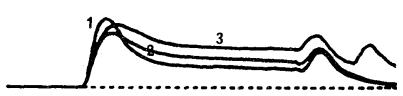

B

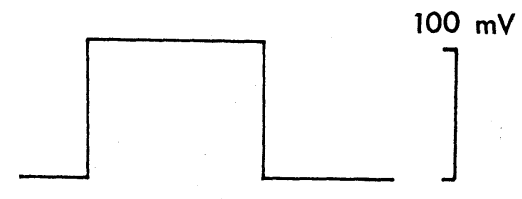

Normal, La $1 \mathrm{mM}$
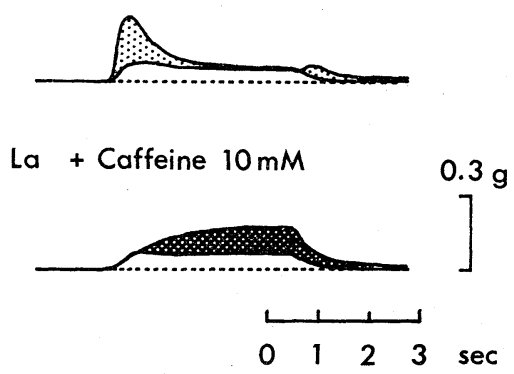

Fig. 8. Effects of caffeine and $\mathrm{La}$ on the tension development during depolarization. A) Tracings of the time course of tension in normal condition and under action of caffeine $(10 \mathrm{~mm})$. Increasing depolarization and corresponding tension were labeled with number. B) Those under action of $\mathrm{La}(1 \mathrm{mM})$, and $\mathrm{La}(1 \mathrm{mM})$ with caffeine $(10 \mathrm{~mm})$. Note an augmentation of the phasic and sustained tensions due to caffeine in A, elimination of phasic tension by $\mathrm{La}$ (stippled area), and enhancement of sustained tension under La with caffeine (cross-hatched area) in B.

obtained $15 \mathrm{~min}$ after the application of tetrodotoxin and $\mathrm{Mn}$. The tension $\left(T_{t}\right)$ at a given time $t$ after the onset of depolarization increased with time until it reached a final value (see inset), and since more than $95 \%$ of the final tension was attained in a few sec after depolarization, the tension at the end of $4.0 \mathrm{sec}$ depolarization was used as a provisional final tension $\left(T_{f}\right)$ as before. Thus, when $T_{f}-T_{t}$ was plotted on a logarithmic scale against $t$, the plots after $0.4 \mathrm{sec}$ appeared on a straight line. Similar exponential relationships were obtained under the action of $\mathrm{La}$ and caffeine. These exponential components are denoted as,

$$
\log \left(T_{f}-T_{t}\right)=-A_{t}+C
$$

and hence

$$
T_{t}=T_{f}\left(1-e^{-t / \tau_{2}}\right)
$$

where $\mathrm{A}$ and $\mathrm{C}$ are constants and $\tau_{2}$ is a time constant of tension development. The time constant, however, varied markedly depending on strength of depolarization, and the stronger the depolarization, the smaller it became (from $0.55 \mathrm{sec}$ for $110 \mathrm{mV}$ to $0.13 \mathrm{sec}$ for $145 \mathrm{mV}$ depolarizations in Fig. 7B). Moreover, the values generally tended to increase with time after application of the drugs. 


\section{DISCUSSION}

The time-course of tension development and decay during depolarization was analysed in the bullfrog atrial muscle, and the results shown in the first section were in general agreement with the earlier findings that the tension during depolarization consists of at least two components, one phasic due to $\mathrm{Ca}$ inward current and the other tonic, unknown in nature (VASSORT and ROUGIER, 1972; LÉOTY and REYMOND, 1972; EINWÄCHTER et al., 1972). The abolition of the phasic contraction for shorter pulse by $\mathrm{La}$ and $\mathrm{Mn}$ ions, and the voltage dependency, in which the peak tension was attained at about $73 \mathrm{mV}$ being depressed for stronger depolarization, reconfirm this view.

Concerning the nature of the second tonic tension component, two possibilities, 1) Ca-influx across the cell membrane and 2) a release of $\mathrm{Ca}$ from intracellular store sites have been suggested. As for the first possibility, however, simple diffusion mechanism of $\mathrm{Ca}$ ions along their electrochemical gradient is unlikely (MoRAD and ORKAND, 1971; EINWÄCHTER et al., 1972; NeW and TraUtWein, 1972b) especially since it failed to explain the tension development at or above the $\mathrm{Ca}$ equilibrium potential of about $+45 \mathrm{mV}$ (BASSINGTHWAIGHTE and REUTER, 1972) to $+120 \mathrm{mV}$ (EINwÄCHTER et al., 1972). This was also the case in our observation. A carrier mediated transport theory, which was first proposed by LÜTTGAU and Niedergerke (1958) and Niedergerke (1963a,b), is attractive as a possible mechanism to overcome the difficulty. Based on theory and flux experiments, REuTER and SEITZ (1968) and Reuter (1970) suggested the presence of a Na-Ca exchange transport system, and HAAs et al. (1970) and EINWÄCHTER et al. (1972), an electrogenic $\mathrm{Ca}$ transport system in the myocardial cell membrane. The problems, either of which mechanism is more plausible, are beyond present scope, however, the observations of the voltage dependency of the tonic tension, the appearance of the tension over $200 \mathrm{mV}$ depolarization, and the dependency of the tension on external $\mathrm{Na}$ and $\mathrm{Ca}$ ions (unpublished observations), strongly support an existence of some carrier mediated $\mathrm{Ca}$ transport across the membrane.

The second possibility of a release of $\mathrm{Ca}$ from intracellular sites, however, could not be totally denied. In the frog myocardium, the rudimentary sarcoplasmic reticulum (SR) is located closely attached to the cell membrane (StAley and Benson, 1968; Sommer and Johnson, 1969). Therefore, in case when this membrane area attached to SR is somehow different from others and the resistance is low or decrease during excitation, a depolarization of the surface cell membrane would be ready to cause some potential change in the SR membrane to induce a release of Ca (BASSIngthwaighte and Reuter, 1972). The situation could be similar to the case of the transverse tubule-SR junction in the skeletal muscle. Our next paper (in preparation), being concerned again with the nature of the tonic tension component, will provide further discussion.

During sustained depolarization, however, a considerably rapid tension fall was noticed in this report, and hence the second tonic tension component ap- 
peared also phasic in the slow records (Figs. 4B, and 8). Phasic or tonic are the terms of relativity, but this simple observation means that despite the continuance of depolarization a withdrawal of $\mathrm{Ca}$ ions from the myoplasm into some internal structure and/or by extrusion of $\mathrm{Ca}$ from the cell by an active transport system occurred.

Concerning the fall of tension during a sustained depolarization, Gото et al. (1971) and MORAD and ORKAND (1971) suggested the possibility that a relaxation between the first and second contractile responses in mammalian myocardium is ascribed to calcium-uptake function of the sarcotubular systems, while in amphibian myocardium the first and second responses are fused because of the paucity of the systems. Even in the latter species, however, the developed tension gradually decays when the depolarization was sustained as noted. This was observed not only on the bullfrog atrium (EINWÄCHTER et al., 1972) but on the frog ventricle under voltage clamp (Gото et al., 1971, Fig. 7). Recently CHAPMAN (1973a, b) analysing the time-course of slow relaxation of the potassium contracture, and Sakai (personal communication) clarifying the rapid cooling contracture in frog myocardium, suggested a presence of energy consuming relaxation process probably due to remnant SR functions or other relaxing factors in these species. Actually, in the frog atrium as in the dog papillary muscle (OHBA, 1973), caffeine in excess concentration $(10 \mathrm{~mm})$ greatly reduced the relaxation during depolarization and enhanced the sustained tension component. Details of the effect of caffeine will be followed in our next paper (Goto et al., in preparation), however, it seems fairly safe to assume that as far as the tension decay is concerned no fundamental difference between the mammalian and amphibian hearts exists and the only apparent difference is a problem in the rate and the capacity of calciumuptake function which is presumed to be small in the amphibian. A prominent tonic tension and an extremely slow decay of the tension during sustained depolarization in the amphibian heart will be explained along this line.

The time constants of tension fall, however, appeared markedly shorter in our case where they were obtained with rectangular depolarization than those determined by CHAPMAN (1973a, b) with K-induced contracture. At the same grade of depolarization $(60 \mathrm{mV})$ our time constant was less than $1.0 \mathrm{sec}$ in comparison with his value $37 \mathrm{sec}$ at room temperature $\left(18-20^{\circ} \mathrm{C}\right)$. Our values almost correspond to those on the relaxation of skeletal muscle fibers which appear to be a time constant of between 1 and $3 \mathrm{sec}$ (Hodgkin and Horowicz, 1960; CAPUTo, 1972). Moreover, the rate of spontaneous relaxation is dependent on the membrane potential and caffeine reduced the relaxation as in the skeletal muscle. These similarities strongly suggest that the tension fall we observed was mainly due to the SR functions as in the skeletal muscle.

Thus, the provisional final tension or sustained tension does not seem to be an independent tension component but a tension in transient equilibrium between the second tonic tension which is determined by the membrane voltage (probably 
relating to Ca-movement across the membrane) and the relaxing function due to the SR which is presumed to be less dependent or independent on the voltage.

In our preceding report (Gото et al., 1972) it was shown that tension fall after termination of rectangular depolarization composed of a few different phases in which the first two main components were exponential. Tension fall "during" depolarization was considered not to be simple because of the simultaneous presence of the tonic tension and relaxing factor as well as some tail effect of the phasic tension. However, when the excess tension $\left(T_{e}\right)$ above the provisional final tension $\left(T_{f}\right)$ during depolarization was plotted against time after the peak, it was found that the fall of excess tension appeared exponential with time (Fig. 6A) and became similar in characteristics to the tension fall after repolarization to various membrane potentials. In other words, the Eq. 1,

$$
T_{e}=\left(T_{m}-T_{f}\right) e^{-t / \tau_{1}}
$$

shows a more generalized form of the Eq. 1 in our preceding report (Goто et al., 1972) and simply means that the excess tension decays exponentially to the final tension which is determined by the membrane potential notwithstanding the case of sustained depolarization or after repolarization.

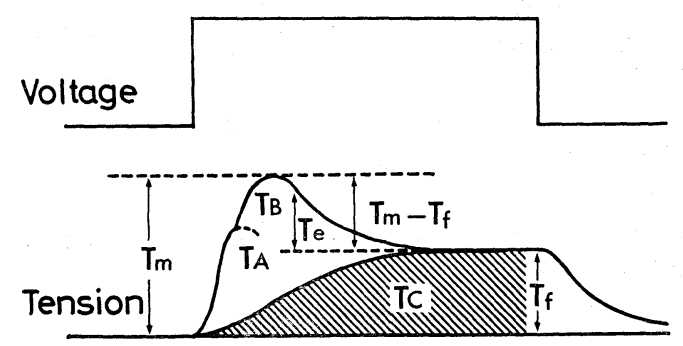

Fig. 9. Schematic illustration of tension components during depolarization. $T_{A}$ : first phasic, $T_{B}$ : second tonic and $T_{C}$ : sustained tension components. $T_{m}$ : maximal tension for a given depolarization, $T_{f}$ : provisional final tension, and $T_{e}$ : excess tension above the provisional final tension. Further explanations are in text.

Since the total tension $\left(T_{\text {tota1 }}\right)$ naturally is a sum of the excess and final tensions, it will be shown,

$$
T_{\text {total }}=T_{e}+T_{f}
$$

and hence,

$$
T_{\text {total }}=T_{m} e^{-t / \tau_{1}}+T_{f}\left(1-e^{-t / \tau_{1}}\right)
$$

In this equation, the first term may correspond to the phasic tension component with relaxation of tension, and the second term, to the tonic tension component without relaxation as schematically illustrated in Fig. 9. The latter component was proved to exist in the frog atrium under action of Mn, D600 (VASSORT and 
RougIER, 1972; LÉOTY and RAYMOND, 1972) and La with caffeine in this report, and the time course of the tonic tension development was actually determined to follow a similar relationship $T_{f}\left(1-e^{-t / \tau}\right)$ as shown in Eq. 2.

However, there is no reason to believe that the time-constant of phasic relaxation, $\tau_{1}$, and that of tonic contraction, $\tau_{2}$, are the same in nature, because the mechanism of tension decay during steady depolarization would be fundamentally different from that of tonic tension development due to depolarization. Actually, the values of $\tau_{1}$ appeared considerably larger than those of $\tau_{2}$, and the former increased with increasing depolarization while the latter decreased (Figs. 6A and 7B). Thus, the equation 4 will be no more than the first approximation to an expression of the time-course of tension decay, but strongly indicate that the tension during sustained depolarization is composed of two elements, one, a relaxation of tension probably due to the SR function, and the other, a tonic tension development $\left(T_{f}\right)$ which is voltage dependent (Fig. 6B).

\section{REFERENCES}

Bassingthwaighte, J. B. and Reuter, H. (1972) Calcium movements and excitation-contraction coupling in cardiac cells. In Electrical Phenomena in the Heart, ed. by DE Mello, W. C. Academic Press, New York and London, pp. 353-395.

BeEler, G. W., Jr. and Reuter, H. (1970) The relation between membrane potential, membrane currents and activation of contraction in ventricular myocardial fibres. J. Physiol., 207: 211229.

Caputo, C. (1972) The time course of potassium contractures of single muscle fibres. $J$. Physiol., 223: 483-505.

CHAPMAN, R. A. (1973a) The ionic dependence of the strength and spontaneous relaxation of the potassium contracture induced in the heart of the frog Rana pipiens. J. Physiol., 231: 209-232.

Chapman, R. A. (1973b) The effects of temperature and metabolic inhibitors on the spontaneous relaxation of the potassium contracture of the heart of the frog Rana pipiens. J. Physiol., 231: 233-249.

EINWÄChTER, H. M., HAAS, H. G. and KeRN, R. (1972) Membrane current and contraction in frog atrial fibres. J. Physiol., 227: 141-171.

Fozzard, H. A. and Hellam, D. C. (1968) Relationship between membrane voltage and tension in voltage-clamped cardiac Purkinje fibres. Nature (Lond.), 218: 588-589.

Gibbons, W. R. and Fozzard, H. A. (1971) Voltage dependence and time dependence of contraction in sheep cardiac Purkinje fibers. Circ. Res., 28: 446-460.

Goto, M., Кімото, Y., and Като, Y. (1971) A study on the excitation-contraction coupling of the bullfrog ventricle with voltage clamp technique. Jap. J. Physiol., 21: 159-173.

Goto, M., KIмото, Y., SAIto, M., and WadA, Y. (1972) Tension fall after contraction of bullfrog atrial muscle examined with the voltage clamp technique. Jap. J. Physiol., 22: 637650 .

HAAS, H. G., KERN, R., and EINwÄChtER, H. M. (1970) Electrical activity and metabolism in cardiac tissue: An experimental and theoretical study. J. Membrane Biol., 3: 180-209.

Hagiwara, S., Takahashi, K., and Junge, D. (1968) Excitation-contraction coupling in a barnacle muscle fiber as examined with voltage clamp technique. J. Gen. Physiol., 51: 157175 . 
Hodgkin, A. L. and Horowicz, P. (1960) Potassium contractures in single muscle fibres. $J$. Physiol., 153: 386-403.

LÉOTY, Cl. and REYMOND, G. (1972) Mechanical activity and ionic currents in frog atrial trabeculae. Pflügers Arch. ges. Physiol., 334: 114-128.

LÜtTGaU, H. C. and Niedergerke, R. (1958) The antagonism between $\mathrm{Ca}$ and $\mathrm{Na}$ ions on the frog's heart. J. Physiol., 143: 486-505.

McGuigan, J. A. S. (1968) Tension in ventricular fibres during a voltage clamp. Helv. Physiol. Pharmac. Acta, 26: CR, 362-363.

Morad, M. and ORKand, R. K. (1971) Excitation-contraction coupling in frog ventricle: Evidence from voltage clamp studies. J. Physiol., 219: 167-189.

New, W. and Trautwein, W. (1972a) Inward membrane currents in mammalian myocardium. Pflügers Arch. ges. Physiol., 334: 1-23.

New, W. and Trautwein, W. (1972b) The ionic nature of slow inward current and its relation to contraction. Pflügers Arch. ges. Physiol., 334: 24-38.

Niedergerke, R. (1963a) Movements of $\mathrm{Ca}$ in frog heart ventricles at rest and during contractures. J. Physiol., 167: 515-550.

Niedergerke, R. (1963b) Movements of $\mathrm{Ca}$ in beating ventricles of the frog heart. J. Physiol., 167: 551-580.

Ochi, R. and Trautwein, W. (1971) The dependence of cardiac contraction on depolarization and slow inward current. Pflügers Arch. ges. Physiol., 323: 187-203.

OнвA, M. (1973) Effects of caffeine on tension development in dog papillary muscle under voltage clamp. Jap. J. Physiol., 23: 47-58.

Reuter, H. (1970) Calcium transport in cardiac muscle. In Permeability and Function of Biological Membranes, ed. by Bolis, L. et al. North-Holland Publ. Co., pp. 342-347.

Reuter, H. and BeEler, G. W. (1969) Calcium current and activation of contraction in ventricular myocardial fibers. Science (Washington), 163: 399-401.

Reuter, H. and Seitz, N. (1968) The dependence of calcium efflux from cardiac muscle on temperature and external ion composition. J. Physiol., 195: 451-470.

Rougier, O., Vassort, G., Garnier, D., Gargouil, Y. M., and Coraboeuf, E. (1969) Existence and role of a slow inward current during the frog atrial action potential. Pflügers Arch. ges. Physiol., 308: 91-110.

Sommer, J. R. and Johnson, E. A. (1969) Cardiac muscle: A comparative ultrastructural study with special reference to frog and chicken hearts. Z. Zellforsch. mikrosk. Anat., 98: 437468.

StAley, N. A. and Benson, E. S. (1968) The ultrastructure of frog ventricular cardiac muscle and its relationship to mechanisms of excitation-contraction coupling. J. Cell Biol., 38: 99114.

Tritthart, H., Kaufmann, R., Volkmer, H.-P., Bayer, R., and Krause, H. (1973) Camovement controlling myocardial contractility. I. Voltage-, current- and time-dependence of mechanical activity under voltage clamp conditions. Pflügers Arch. ges. Physiol., 338: 207-231.

VASSORT, G. and RougIER, O. (1972) Membrane potential and slow inward current dependence of frog cardiac mechanical activity. Pflügers Arch. ges. Physiol., 331: 191-203. 